\title{
Redox state of albumin is not associated with colloid osmotic pressure
}

\author{
MASAHIRO SAKATA ${ }^{1}$, TAKUMI KAWAGUCHI ${ }^{1,2}$, EITARO TANIGUCHI $^{1}$, AKIRA NAKAYAMA $^{4}$, \\ SONOKO ISHIZAKI ${ }^{4}$, ICHIRO SONAKA ${ }^{4}$, MIYAKO MAGANUMA ${ }^{5}$, TORU NAKAMURA ${ }^{1}$, \\ MINORU ITOU $^{1}$, TETSUHARU ORIISHI ${ }^{1}$, MITSUHIKO ABE ${ }^{1}$, CHIKATOSHI YANAGIMOTO ${ }^{1}$, \\ HIRONORI KOGA ${ }^{1}$, MASARU HARADA ${ }^{6}$, TERUO SAKAMOTO ${ }^{3}$, SHIGETO ODA ${ }^{5}$ and MICHIO SATA ${ }^{1,2}$
}

${ }^{1}$ Division of Gastroenterology, Department of Medicine, Departments of ${ }^{2}$ Digestive Disease Information and Research, and ${ }^{3}$ Emergency and Critical Care Medicine, Kurume University School of Medicine, Kurume, Fukuoka 830-0011; ${ }^{4}$ Pharmaceutical Research Laboratories, Ajinomoto Co., Inc., Kanagawa 210-0801; ${ }^{5}$ Department of Emergency and Critical Care Medicine, Chiba University Graduate School of Medicine, Chiba 260-8670; ${ }^{6}$ Third Department of Internal Medicine, University of Occupational and Environmental Health, School of Medicine, Kitakyushu 807-8555, Japan

Received February 16, 2010; Accepted May 10, 2010

DOI: $10.3892 / \mathrm{mmr} 00000317$

\begin{abstract}
Serum albumin exists in oxidized and reduced forms. Although the oxidation of albumin affects some of its functions, the relationship between oxidized albumin and colloid osmotic pressure (COP) remains unclear. The aim of this study was to determine whether there is an association between oxidized albumin and COP. Blood samples from 20 healthy volunteers were divided into two aliquots in order to prepare reduced $(n=20)$ and oxidized albumin samples $(n=20)$. This was achieved by treatment with L-cysteine and a redox-stabilizing agent before and after incubation at $37^{\circ} \mathrm{C}$ for $24 \mathrm{~h}$. The percentage of oxidized albumin was determined by high-performance liquid chromatography. COP was measured using a colloid osmometer. Reduced and oxidized albumin samples showed $100 \%$ of reduced and $100 \%$ of oxidized albumin, respectively. There were no significant differences in albumin level and total protein level between the reduced and the oxidized albumin samples. No significant change was seen in COP between the reduced and the oxidized albumin samples (reduced albumin, 17.4 $\pm 0.2 \mathrm{mmHg}$; oxidized albumin, $17.3 \pm 0.2 \mathrm{mmHg} ; \mathrm{P}=0.465)$. Therefore, there is no significant difference in COP between reduced and oxidized albumin samples.
\end{abstract}

Correspondence to: Dr Masahiro Sakata, Division of Gastroenterology, Department of Medicine, Kurume University School of Medicine, 67 Asahi-machi, Kurume 830-0011, Japan E-mail: sakata_masahiro@med.kurume-u.ac.jp

Abbreviations: COP, colloid osmotic pressure; HPLC, highperformance liquid chromatography; HSA, human serum albumin

Key words: oxidized albumin

\section{Introduction}

Human serum albumin (HSA) is synthesized by hepatocytes and is the most abundant protein in plasma. HSA acts not only as a transporter of various substances, but also as a component of colloid osmotic pressure (COP) $(1,2)$. COP is an important factor that regulates the movement of fluids between intravascular and extravascular spaces (3). Since large plasma proteins cannot easily cross through the capillary walls, their effect on the osmotic pressure of the capillary interiors tends to pull fluid into the capillaries (4). HSA accounts for $80 \%$ of plasma COP, therefore it is believed that a decrease in serum albumin levels leads to low COP, which is associated with the development of fluid retention in the interstitial space or so-called edema (5). However, edema cannot always be explained by decreases in the serum albumin level (6).

HSA is divided into two forms according to the redox state of the Cys-34 locus of HSA: reduced albumin (human mercaptalbumin) and oxidized albumin (human non-mercaptalbumin). This has been demonstrated by high-performance liquid chromatographic (HPLC) analysis (7). In healthy adults, approximately $75 \%$ of the Cys-34 molecules in albumin contain a free sulfhydryl group (reduced albumin), while approximately $25 \%$ (oxidized albumin) form a disulfide with small sulfhydryl compounds, such as another cysteine, homocysteine or glutathione (8). Not only the quantity, but also the quality of albumin have been previously discussed $(9,10)$. Oxidized albumin clearance in the body is more rapid compared to reduced albumin (11). In addition, ligand binding and antioxidant capacity are lower in oxidized than in reduced albumin (12). Thus, the oxidation of HSA is associated with structural and functional changes.

Recently, we reported that oxidized albumin is associated with edema in cirrhosis (13). Although one would think that the ability to synthesize albumin decreases with disease progression, leading to edema in cirrhotic patients, it remains unclear whether the oxidation of albumin directly affects 
Table I. Reduced and oxidized albumin percentage of albumin samples treated with redox-stabilizing agent and L-cysteine.

\begin{tabular}{lrrr}
\hline & $\begin{array}{c}\text { Reduced } \\
\text { samples } \\
(\mathrm{n}=20)\end{array}$ & $\begin{array}{c}\text { Oxidized } \\
\text { samples } \\
(\mathrm{n}=20)\end{array}$ & P-value \\
\hline Oxidized albumin $(\%)$ & $0 \pm 0$ & $100 \pm 0$ & $<0.01$ \\
Reduced albumin (\%) & $100 \pm 0$ & $0 \pm 0$ & $<0.01$ \\
\hline
\end{tabular}

Table II. Comparison of laboratory data between reduced and oxidized albumin samples.

\begin{tabular}{lccc}
\hline & $\begin{array}{c}\text { Reduced } \\
\text { samples } \\
(\mathrm{n}=20)\end{array}$ & $\begin{array}{c}\text { Oxidized } \\
\text { samples } \\
(\mathrm{n}=20)\end{array}$ & P-value \\
\hline Total protein $(\mathrm{g} / \mathrm{dl})$ & $6.30 \pm 0.10$ & $6.20 \pm 0.10$ & 0.193 \\
Serum albumin $(\mathrm{g} / \mathrm{dl})$ & $4.06 \pm 0.06$ & $4.05 \pm 0.08$ & 0.882 \\
$\begin{array}{l}\text { Colloid osmotic } \\
\text { pressure }(\mathrm{mmHg})\end{array}$ & $17.4 \pm 0.20$ & $17.3 \pm 0.20$ & 0.465 \\
\hline
\end{tabular}

COP. The aim of this study was to determine whether the redox state of albumin affects COP.

\section{Materials and methods}

Preparation of reduced and oxidized human serum albumin samples. Blood samples from 20 healthy adult volunteers (11 females and 9 males) were each divided into two aliquots in order to prepare reduced $(n=20)$ and oxidized $(n=20)$ albumin samples. Redox-stabilizing agent was prepared as previously described (14).

Reduced albumin samples. Samples were exposed to $1 \mathrm{mmol} / \mathrm{ml}$ L-cysteine (Sigma-Aldrich, St. Louis, MO, USA) and to redox-stabilizing agent simultaneously, and the mixture was incubated at $37^{\circ} \mathrm{C}$ for $24 \mathrm{~h}$. Thereafter, samples were stored at $-20^{\circ} \mathrm{C}$ until analysis.

Oxidized albumin samples. Samples were exposed to $1 \mathrm{mmol} / \mathrm{ml} \mathrm{L}$-cysteine and the mixture was incubated at $37^{\circ} \mathrm{C}$ for $24 \mathrm{~h}$. Thereafter, samples were mixed with the redoxstabilizing agent and stored at $-20^{\circ} \mathrm{C}$ until analysis.

Laboratory determinations. Blood samples were taken from the peripheral vein of the subjects while they were in the sitting position. After the oxidation or reduction treatment, plasma albumin levels were measured using nephelometry and plasma total protein levels were measured using Biuret methods $(15,16)$. In untreated healthy human blood samples, the reference value of plasma albumin is 3,900-4,900 $\mathrm{mg} / \mathrm{dl}$; for the plasma total protein level, it is $6.7-8.3 \mathrm{~g} / \mathrm{dl}$.

Determination of oxidized and reduced albumin. HPLC was performed using $5 \mu \mathrm{l}$ aliquots of each plasma sample and a Shodex Asahipak ES-502N column (Showa Denko, Tokyo, Japan; column temperature $35 \pm 0.5^{\circ} \mathrm{C}$ ). The HPLC system consisted of a Model SCL-10Avp system controler, a Model
A

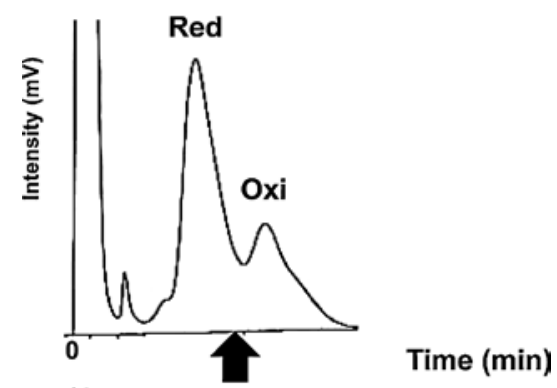

B

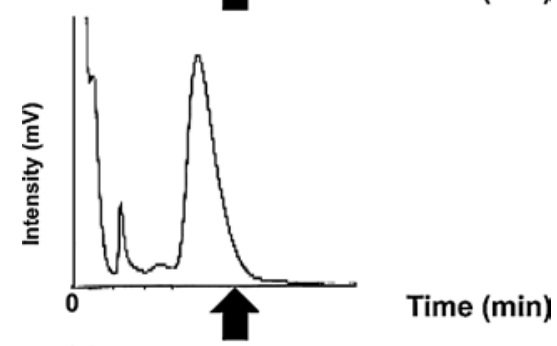

C

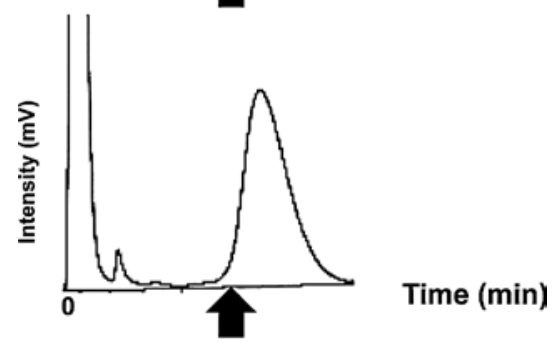

Figure 1. Representative chromatograms of L-cysteine-treated albumin samples. (A) Before treatment ( $\mathrm{n}=4)$. (B) Reduced albumin sample $(\mathrm{n}=4)$. (C) Oxidized albumin sample $(n=4)$. The arrow indicates 20 min past elution. Red, reduced albumin; Oxi, oxidized albumin.

LC-10ATvp double-plunger pump with a Model FCV-10ALvp gradient and a Model SCL-10ADvp autosampler, a Model RF-10AXL fluorescence detector (excitation wavelength $280 \mathrm{~nm}$; emission wavelength $340 \mathrm{~nm}$ ). All instruments were purchased from Shimadzu Co. (Tokyo, Japan). Elution was carried out with a linear gradient of increasing ethanol concentration $0-5 \%$, in $0.05 \mathrm{M}$ sodium acetate- $0.40 \mathrm{M}$ sodium sulfate (pH 4.85) (acetate-sulfate buffer) at a flow rate of $1 \mathrm{ml} / \mathrm{min}$.

Determination of colloid osmotic pressure. The colloid osmometer (Colloid 4420 ${ }^{\circledR}$; Wescor, UT, USA) was used to directly measure colloid osmotic pressure (17). To examine the reproducibility of measurements, COP was measured twice for each sample and the values were expressed as the means (Table II).

\section{Results}

Oxidized albumin percentage of L-cysteine treated samples. After treatment with L-cysteine + redox-stabilizing agent, the proportion of samples that were reduced albumin became $100 \%$. After treatment with L-cysteine without redox-stabilizing agent, the proportion of samples that were oxidized albumin became $100 \%$ (Table I and Fig. 1).

Albumin levels, total protein levels and colloid osmotic pressure in the reduced and oxidized samples. Data for the outcome variables are summarized in Table II. There were no significant differences in albumin levels and total protein levels between the reduced and oxidized albumin samples. 
Similarly, there was no significant difference in COP between the two groups. Thus, none of the variables differed between reduced and oxidized albumin samples.

\section{Discussion}

In this study, we investigated the association between the oxidation of albumin and COP using $100 \%$ reduced and $100 \%$ oxidized albumin samples. There was no significant difference in COP between reduced and oxidized albumin samples.

The method for preparing $100 \%$ oxidized and $100 \%$ reduced albumin samples involved L-cysteine. Since cysteine has an $\mathrm{SH}$ residue, treatment with L-cysteine caused the albumin to shift to the reduced form, indicating that cysteine acted as a reductant. Incubation at $37^{\circ} \mathrm{C}$ for $24 \mathrm{~h}$ caused albumin to became oxidized; since cystine (Cys-S-S-Cys) is produced under oxidizing conditions, the result is a shift of the albumin to the oxidized form. With these preparation methods, the only difference between the oxidized and reduced albumin samples was that, in the reduced samples, the cysteine formed disulfide bond with Cys34. Following treatment with L-cysteine, there were no significant differences in the albumin levels or total protein levels between the two groups. However, the concentrations of albumin and total protein decreased compared to the reference values of each parameter. One possible reason is that the samples were diluted by treatment with the redox-stabilizing agent.

We investigated a possible association between the oxidation of albumin and changes in COP. However, no significant difference in COP was detected between the reduced and oxidized albumin samples. COP is the equilibrium pressure exerted on a semi-permeable membrane separating two solutions of differing osmolality. Fluids pass across these membranes, while larger materials, such as proteins (also known as colloids), cannot (18). The molecular mass of human albumin is approximately 66,000, while the molecular mass of L-cysteine is 121.16. It is thought that there is little difference between the molecular mass of oxidized and reduced albumin. COP is dependent on the total concentration of molecules dissolved in a fluid (19). In this study, the concentrations of total protein and albumin did not differ between the reduced and oxidized samples. Therefore, the oxidation of albumin may not have influenced COP. We previously reported that oxidized albumin is associated with edema in cirrhosis (13). In line with this thinking, the indirect influence of albumin oxidation, such as drug binding properties and oxidative stress, may have been related to edema formation $(11,20)$.

In conclusion, we investigated a possible association between the redox state of albumin and COP using 100\% oxidized and $100 \%$ reduced albumin samples. However, we found that the oxidation of albumin is not associated with changes in COP.

\section{Acknowledgments}

The authors thank Drs Yuichiro Higashimoto, Hideaki Sato and Masato Noguchi (Department of Medical Biochemistry, Kurume University School of Medicine) for technical assistance and helpful discussions. This study was supported in part by a Grant-in-Aid for Young Scientists (B) (No. 19790643 to T.K.) and a Grant-in-Aid for Scientific Research (C) (No. 21590865 to M.S.) from the Ministry of Education, Culture, Sports, Science and Technology of Japan, by the Health and Labour Sciences Research Grants for Research on Hepatitis from the Ministry of Health, Labour and Welfare of Japan, and by a Grant for Cancer Research from the Fukuoka Cancer Society.

\section{References}

1. Rothschild M, Oratz M and Schreiber S: Serum albumin. Hepatology 8: 385-401, 1988.

2. Kragh-Hansen U: Structure and ligand binding properties of human serum albumin. Dan Med Bull 37: 57-84, 1990.

3. Krogh A, Landis EM and Turner AH: The movement of fluid through the human capillary wall in relation to venous pressure and to the colloid osmotic pressure of the blood. J Clin Invest 11: 63-95, 1932.

4. Vercueil A, Grocott MP and Mythen MG: Physiology, pharmacology, and rationale for colloid administration for the maintenance of effective hemodynamic stability in critically ill patients. Transfus Med Rev 19: 93-109, 2005.

5. Coward W: Serum colloidal osmotic pressure in the development of kwashiorkor and in recovery: its relationship to albumin and globulin concentrations and oedema. Br J Nutr 34: 459-467, 1975.

6. Noguera Vinas EC, Hames W, Mothe G and Barrionuevo MP Extracellular fluid, plasma and interstitial volume in cirrhotic patients without clinical edema or ascites. Medicina 49: 320-324, 1989.

7. Sogami M, Era S, Nagaoka S, et al: Hplc-studies on nonmercaptmercapt conversion of human serum albumin. Int J Pept Protein Res 25: 398-402, 1985.

8. Beck J, Ambahera S, Yong S, Sheil M, de Jersey J and Ralph S: Direct observation of covalent adducts with cys34 of human serum albumin using mass spectrometry. Anal Biochem 325: 326-336, 2004

9. Shaklai N, Garlick R and Bunn H: Nonenzymatic glycosylation of human serum albumin alters its conformation and function. $\mathrm{J}$ Biol Chem 259: 3812-3817, 1984.

10. Yamada N, Nakayama A, Kubota K, Kawakami A and Suzuki E: Structure and function changes of oxidized human serum albumin: physiological significance of the biomarker and importance of sampling conditions for accurate measurement. Rinsho Byori 56: 409-415, 2008.

11. Iwao Y, Anraku M, Hiraike M, et al: The structural and pharmacokinetic properties of oxidized human serum albumin, advanced oxidation protein products (aopp). Drug Metab Pharmacokinet 21: 140-146, 2006.

12. Kawakami A, Kubota K, Yamada N, et al: Identification and characterization of oxidized human serum albumin. A slight structural change impairs its ligand-binding and antioxidant functions. FEBS J 273: 3346-3357, 2006.

13. Sakata M, Kawaguchi T, Taniguchi E, et al: Oxidized albumin is associated with water retention and severity of disease in patients with liver cirrhosis. Gastroenterology 134: A793-A793, 2008.

14. Kubota K: A simple stabilization method of reduced albumin in blood and plasma for the reduced/oxidized albumin ratio measurement. Int J Biomed Sci 5: 293-301, 2009.

15. Okutucu B, Dincer A, Habib O and Zihnioglu F: Comparison of five methods for determination of total plasma protein concentration. J Biochem Biophys Methods 70: 709-711, 2007.

16. Deaton CD, Maxwell KW, Smith RS and Creveling RL: Use of laser nephelometry in the measurement of serum proteins. Clin Chem 22: 1465-1471, 1976.

17. Blackwell MM, Riley J, McCall M, Ecklund J and Southworth R: An evaluation of three methods for determining colloid osmotic pressure. J Extra Corpor Technol 26: 18-22, 1994.

18. Krediet RT, Ho-dac-Pannekeet MM, Imholz AL and Struijk DG: Icodextrin's effects on peritoneal transport. Perit Dial Int 17: 35-41, 1997.

19. Sinclair $S$ and Webb AR: Colloid osmotic pressure measurement in critically ill patients. Intensive Care World 8: 120-122, 1991.

20. Banday A and Lokhandwala M: Oxidative stress-induced renal angiotensin at 1 receptor upregulation causes increased stimulation of sodium transporters and hypertension. Am J Physiol Renal Physiol 295: F698-F706, 2008. 